\title{
Quality assurance and the home market effect
}

\author{
Ai-Ting Goh and Tomasz Michalski \\ HEC Paris
}

August 31, 2008

\begin{abstract}
The home market effect is considered as a distinguishing feature of models of trade with increasing returns to scale in production and imperfect competition. However, some empirical studies found the existence of home market effect even in constant returns to scale industries. In this paper we build a model of intra-industry trade based upon quality assurance and show the existence of the home market effect without increasing returns in the production technology. This throws into question the rationale of empirical studies attempting to validate the increasing returns model of trade based upon testing the existence of the home market effect.

Keywords: home market effect, intra-industry trade, quality assurance

JEL classification: F1, R3
\end{abstract}




\section{Introduction}

The new trade theory has identified increasing returns to scale in production and imperfect competition as reasons for countries to trade. Since the development of this theory, several attempts have been made to assess empirically the importance of increasing returns as a determinant of trade. Early empirical works focused on the predictions of the theory regarding trade flows but yielded mixed results mainly because some of the predictions of the new trade theory are similar to that of comparative advantage models (see for example Davis 1995). Hence more recent empirical works focus on one distinguishing feature of the new trade theory - the home market effect which was first demonstrated in Krugman (1980) and subsequently further elaborated upon in Helpman and Krugman (1985). The home market effect refers to the tendency for differentiated good industries to be concentrated in the larger country in a trading pair making it a net exporter of these goods. The home market effect arises in a model with increasing returns and trade costs because firms choose to produce in only one location to take advantage of scale economies and they locate where the market size is larger to save on transport costs. The home market effect does not arise in comparative advantage models with perfect competition and constant returns to scale technology. Subsequent theoretical research on the home market effect studies its robustness under different assumptions concerning transport costs, type of competition, utility functions etc. (see for examples, Feenstra et al. 2001, Head et al. 2002 and Yu 2005). The conclusion from this literature is that increasing returns is necessary but not sufficient for the existence of home market effects.

Recent empirical works by Feenstra et al. (2001), Davis and Weinstein (1999, 2003) and Hanson and Xiang (2004) have provided support for the home market effect and thus, as claimed by the authors, indirectly supported the increasing returns theory of trade. For example, Head and Mayer (2004) in their survey of the literature note "Models of comparative advantage with constant returns are inconsistent with the magnifying effect of market size, (the presence of the latter) supports increasing returns model." However, a closer scrutiny of the results presented for example in Davis and Weinstein (2003) reveals that home market effects are present even in industries that other empirical works have found to exhibit constant returns to scale production technology. For example, Antweiler and Trefler (2002) use a variant of the Vanek equation to estimate returns to scale at a sectoral level and found constant returns to scale in industries such as food preparation, leather products and textiles which also exhibit the home market effect in Davis and Weinstein's studies.

To see whether the results in Davis and Weinstein (2003) are repeated with more recent data, we ran a simple fixed effects panel regression of 3-digit industry production shares in total production on industry demand shares in total demand for 25 OECD countries for the period 1980-2003. For an industry $i$ in country $j$ the estimated regression (1) is: 


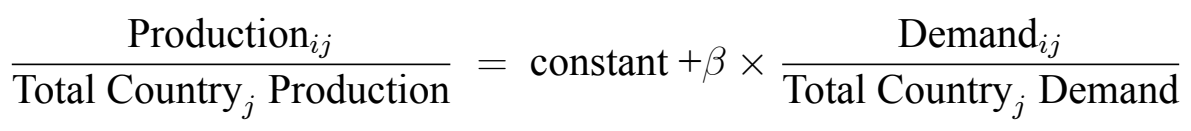

where Demand ${ }_{i j}$ is equal to the production in the industry $i$ in country $j$ minus exports plus imports of goods.

The results of the regression are shown in Table 1. We are interested in the slope coefficient $\beta$ for each 3-digit industry. $\beta>1$ implies that a higher share of an industry in domestic demand leads to an even higher share in production on average (and to the country being a net exporter of the good) and hence signifies a potential home market effect in that industry. We notice that for "Leather, leather products and footwear" and "Textiles and textile products" we have the coefficient on the demand share $\beta>1$, similar to that reported in Davis and Weinstein (2003).

The available evidence is obviously inconsistent with the received conclusion in the literature that increasing returns in production is necessary for the home market effect. Even if the degree of increasing returns in such industries as textiles and leather products would be small, we might not observe the home market effect in these industries. This is because in this case, firms will prefer to split their production in the different countries rather than to concentrate production since the gains from economies of scale in production will be small and hence likely to be outweighed by the gains from saving on transport costs by producing in multiple locations. The evidence is also inconsistent with the type of models as in Ethier (1982) or Helpman and Krugman (1985) whereby the home market effect may be observed for constant (internal) returns to scale industries that use non tradeable inputs produced under increasing returns to scale. This is because in this case, the constant returns industries will then experience increasing returns at the sectoral level - as more units are produced, the lower are the costs of producing for those industries as more input varieties are available. The study by Antweiler and Trefler (2002) takes into account both internal and external increasing returns and still it finds constant returns on the sectoral level for some industries where home market effects were found.

How then can one explain the presence of home market effects in constant returns to scale industries? In this paper we develop two models of intra-industry trade in horizontally differentiated goods based upon quality assurance and without increasing returns to scale in production and show that the home market effect can arise. Increasing returns in production technology is thus not necessary for the existence of the home market effect.

The starting point of our paper is the observation that an important feature of differentiated products is that their quality is often not easily observed as opposed to homogenous goods (corn, oil) where quality is relatively easy to infer. Many such products are experience goods, where the quality is learnt by buyers only after some usage (footwear, car parts, furniture, light bulbs...). The presence of imperfect information implies that if firms have a choice of whether to sell or not the 
Table 1: Regression results of production share of an industry in total production on its demand share in total demand for 25 OECD countries in the period 1980-2003.

\begin{tabular}{lccc}
\hline \hline Manufacturing Industry & $\begin{array}{c}\text { Coefficient } \\
\beta\end{array}$ & $\begin{array}{c}\text { Standard } \\
\text { error }\end{array}$ & $\begin{array}{c}\text { No. of } \\
\text { observations }\end{array}$ \\
\hline \hline Basic metals & .843 & .026 & 426 \\
Chemicals and chemical products & .885 & .047 & 411 \\
Coke, refined petroleum products and nuclear fuel & .713 & .048 & 407 \\
Electrical and optical equipment & 1.100 & .027 & 417 \\
Fabricated metal products, excl. machinery and equipment & 1.132 & .021 & 425 \\
Food products and beverages & .811 & .103 & 339 \\
Leather, leather products and footwear & 1.709 & .021 & 434 \\
Machinery and equipment, n.e.c. & 1.082 & .059 & 417 \\
Motor vehicles, trailers and semi-trailers & 1.518 & .028 & 399 \\
Other transport equipment & .734 & .023 & 399 \\
Paper and paper products & 3.030 & .074 & 414 \\
Publishing, printing and reproduction of recorded media & .916 & .016 & 418 \\
Rubber and plastics products & .829 & .029 & 434 \\
Textiles and textile products & 1.566 & .018 & 434 \\
Tobacco products & 1.267 & .036 & 399 \\
\hline \hline
\end{tabular}

Data source: OECD databases National Accounts of OECD countries and STAN database

products they know are faulty and/or have a choice of the production technology that differentiates quality, they will have incentives to sell low quality at high quality prices if low quality costs less to produce. Under such circumstances, prices need not convey any information and hence an institutional set up needs to be found to overcome this moral hazard problem so that high quality products will be produced in equilibrium.

We consider first a simple one period model whereby firms that sell a low quality product may be discovered by consumers with a probability that depends positively on the quantity sold. If a firm is discovered producing low quality, all its products are recalled and consumers get a refund from the firm. This implies that as the quantity sold increases, the profit of a firm producing high quality increases relative to that selling low quality. A large enough market demand for a given firms' products will ensure that firms have the right incentives to provide high quality. Thus an incentive compatibility constraint limits the number of high quality firms that can exist in equilibrium regardless of their production technology and gives rise to an endogenous industrial structure even with a constant returns to scale production technology and no fixed costs of entry.

The industrial organization literature has provided another solution to the problem of quality 
assurance based upon reputation acquisition in a repeated purchase framework (see papers by Klein and Leffler (1981), Shapiro (1983), Allen (1984) and Farrell (1986)) to which we turn next. Firms producing high quality command a quality premium so that they have incentives not to lower the quality for fear that consumers will retaliate and not repeat the purchase of their products. In the second model we follow the industrial organization literature and assume that the incentive to produce high quality is provided by a sufficiently high premium with repeated purchases. We assume that the entry of additional firms reduces the market power and hence the equilibrium markup of existing firms. The industry can therefore only sustain a finite number of firms as otherwise firms will not earn sufficient rents to want to produce the high quality good.

We then incorporate the two alternative solutions to the quality assurance problem into a model of trade with two goods and one factor of production. We consider two economies that produce a homogenous good and a differentiated good. Consumers' preferences for the (high quality) differentiated good exhibit love for variety à la Dixit and Stiglitz (1977). The homogenous good is produced under constant returns and perfect competition while the differentiated good is produced with constant returns technology and monopolistic competition. There is an iceberg trade cost for shipping the differentiated good but no transport cost for the homogenous good. ${ }^{1}$ For trade in differentiated goods to occur there must be a reason for firms to want to concentrate their production in one location rather than to produce in two locations to avoid the transport costs. In the increasing returns model, this incentive arises due to plant scale economies that outweigh the savings in transport costs. We provide two reasons why firms may want to concentrate production. In the one period model, we assume that goods coming from the same firm but different production plants (locating in different countries) are perceived as being of potentially different qualities and that firms cannot precommit to producing the same quality in all the different plants. This implies that if a firm has different production sites, it has to make the quality choice decision for each separate plant. In other words, instead of one incentive constraint applying to a firm's global sales, the incentive compatibility constraint for high quality production must be satisfied for each production establishment. Thus firms will want to concentrate production in one location so as to increase sales making it easier to satisfy the incentive constraint to produce high quality. In the multiperiod model, we assume that exports take time to arrive at the foreign country so that domestic consumers would have purchased and known the quality of the good before the good reaches the foreign consumers. If domestic consumers found out that the good is of low quality, the news would spread to the foreign country so that foreign sales would be affected. A firm which concentrates its production in one location and exports then has more incentives to produce high quality compared to a firm which splits production because producing low quality would be pe-

\footnotetext{
${ }^{1}$ We are aware that if there are transport costs on the homogenous good (as in Davis 1998), the home market effect will disappear from our model.
} 
nalised more heavily by reduced foreign sales. In equilibrium with free entry, only firms which concentrate production in one location will be able to satisfy the incentive compatibility constraint and hence sell their goods.

Starting from a proportional equilibrium where the share of differentiated goods firms in each country is proportional to its share of world demand, firms in the larger market will have larger sales because they will face lower average trade costs on their sales. Since larger sales increase the probability of being found if the product is of low quality, the incentive constraint of firms in the larger market will be slack if the one for firms located in the smaller market is binding. Additional firms can thus enter in the large country without violating the incentive compatibility constraint. The larger country will thus have a larger than proportional share of differentiated good firms giving rise to the home market effect. This is similar in spirit to the increasing returns model whereby starting from the proportional equilibrium firms in the larger market earn strictly higher profits due to lower transport costs and hence more firms can enter the larger market giving rise to the home market effect. However, in our model, the production technology of the firm does not matter. In particular, the firms can have constant returns to scale technology and yet the home market effect still obtains. ${ }^{2}$ In the multiperiod model, the number of firms in equilibrium is determined by an incentive compatibility constraint (in contrast to the existence of a fixed cost or the production efficiency - variety tradeoff in the increasing returns model) and the home market effect arises for exactly the same reason as in the increasing returns model.

The rest of the paper is organized as follows. Section 2 sets up the one period model and derives the autarky equilibrium. Section 3 derives the free trade equilibrium and shows the existence of the home marker effect. In section 4 we consider a multiperiod setting and discuss the home market effect. Section 5 concludes.

\section{A model}

\subsection{Consumers}

We present a simple model of monopolistic competition, international trade and quality assurance. The world lasts only one period. There are homogenous and differentiated goods (which can be either of low or high quality) that enter the utility function of each consumer. We assume that $L$ consumers have preferences of the Dixit-Stiglitz love-of-variety type over differentiated goods.

\footnotetext{
${ }^{2}$ In fact, we can easily construct an example where firms have decreasing returns to scale technology and yet the home market effect obtains (see Appendix A.2). This runs contrary to the claim by Krugman (1980) that a home market effect is not possible with decreasing returns to scale technology.
} 
The utility function is

$$
U=\left(\sum_{k>0}\left(c_{k} s_{k}\right)^{\sigma}\right)^{\frac{\gamma}{\sigma}}\left(c_{0}\right)^{1-\gamma}
$$

where $0<\sigma<1$ is one minus the inverse of the demand elasticity between $k$ different varieties of the differentiated good, $0<\gamma<1$ is the budget share spent on differentiated goods, $c_{0}$ is the planned consumption of the homogenous good, $c_{k}$ is the planned consumption of the (high quality) variety $k$ and $s_{k}=1$ if product $k$ is of high quality and zero otherwise. Note that the utility function exhibits a scale effect in the sense that a greater variety of differentiated goods consumed keeping total consumption of the differentiated good constant will increase utility. This scale effect does not in anyway drive the results that follow. We could remove the scale effect as in Benassy (1998) and all the results will still hold. We choose to maintain the usual formulation of the utility function for the ease of comparison with the existing literature.

The utility maximization problem on the side of the consumer leads to the following demand for the differentiated product of high quality and a homogenous good respectively:

$$
\begin{gathered}
c_{k}=\frac{I}{L} \frac{\gamma\left(p_{k}\right)^{-\frac{1}{1-\sigma}}}{\left(\sum_{k}\left(p_{j}\right)^{-\frac{\sigma}{1-\sigma}}\right)} \\
c_{0}=\frac{I}{L} \frac{(1-\gamma)}{p_{0}}
\end{gathered}
$$

where $I$ is economywide income, $p_{k}$ is the price of variety $k$ and $p_{0}$ is the price of the homogenous good.

There is one factor of production used in both the homogenous and the differentiated good sector - labor - which receives wages $w$ (normalized to 1) for its services. Labor also receives any profits the firms might generate worldwide (they hold perfectly internationally diversified portfolios).

\subsection{Production}

The homogenous good is produced under constant returns to scale technology and perfect competition. There is no entry cost into this sector. The quality of the homogenous good is perfectly verifiable by the buyers; hence there is no quality assurance problem in this market. ${ }^{3}$

The differentiated good sector operates under monopolistic competition. As consumers value variety each entrant in its interest would want to produce a different variety from the ones that are

\footnotetext{
${ }^{3}$ Rauch (1999) defines in his study homogenous goods as those that are traded on organized exchanges. This feature is possible only when the goods in question have a quality that is easily and/or cheaply measurable and parametrizable.
} 
offered on the market since inventing a new variety is costless. There are no sunk costs of entry into the differentiated good industry.

\subsection{The quality assurance problem}

There is a quality assurance problem in the differentiated good market. Each firm apart from the pricing decision decides at the same time about producing high or low quality of its variety of the differentiated good. ${ }^{4}$

Producing any quantity of low quality products involves lower costs than the same quantity of high quality products. The marginal cost of production is assumed to be constant in the production of both high and low quality goods. Denoting the marginal cost by $\psi$ we have $\psi_{H}>\psi_{L}>0$ with subscripts $H$ and $L$ standing for the high and low quality respectively. Firms compare the profits from high quality good production $\Pi_{H}$ with the profits $\Pi_{L}$ of cheating and misinforming consumers. If $\Pi_{H}>\Pi_{L}$ then the firm decides to produce the high quality good and low quality otherwise.

Consumers cannot verify the quality of any differentiated good directly upon purchase. We assume, however, that within some time after purchase consumers may through regular use learn whether the product is of low quality with some probability. We assume that this probability has a log-logistic distribution with the scale parameter $\alpha>0$ and the shape parameter $\beta>0$. The probability that none of the consumers after buying discovers that the product is of low quality is then $\frac{\alpha^{\beta}}{(q(p))^{\beta}+\alpha^{\beta}}$ where $q(p)$ signifies the demand for the good when it is believed by consumers to be of high quality. ${ }^{5}$ If the good is discovered to be of low quality, this information spreads, the product is recalled and consumers obtain a refund from the firm. This refund is equal to some $\varpi$ per unit; it is influenced by laws, costs of recalling and the compensation required by consumers. In what follows, we assume that $\varpi+\psi_{L} \geq \psi_{H}$ i.e. that it does not pay to cheat for the firm if it would know for sure that it is going to be found out. Otherwise, all firms would have always an incentive to cheat and the whole market for high quality differentiated goods would unravel.

\footnotetext{
${ }^{4}$ We are concerned here only with the moral hazard problem in the firm and not the adverse selection problem. We do not take a stance of why this problem arises: whether it is a problem of correct principal-agent incentives within the firm or whether it is the owner of the firm directly that wishes to cheat on the customers.

Examples of both abound. For example, Cadbury managers may have knowingly hidden the discovery of salmonella contained in chocolate produced in their plants that was later put on the market in the United Kingdom (Financial Times, 14 July 2007). Mattel faced problems with Chinese contractors and subcontractors that wanted to save on costs and included lead paint for toys instead of the paint approved by Mattel (New York Times, 15 August 2007).

${ }^{5}$ Detection of low quality products is not straightforward. Consider the discovery of poisonous ingredients in toothpaste by a Panaman consumer (New York Times, 1 October 2007) which was sold worldwide at the time. The toothpaste was later recalled in 34 countries.

In many cases, for example with sickness or injury, it is only after the incidence of repeated cases when a quality problem with a particular product causing the problem can be established (New York Times, 15 July 2007). This means that with larger sales it is more probable to detect low-quality products.
} 


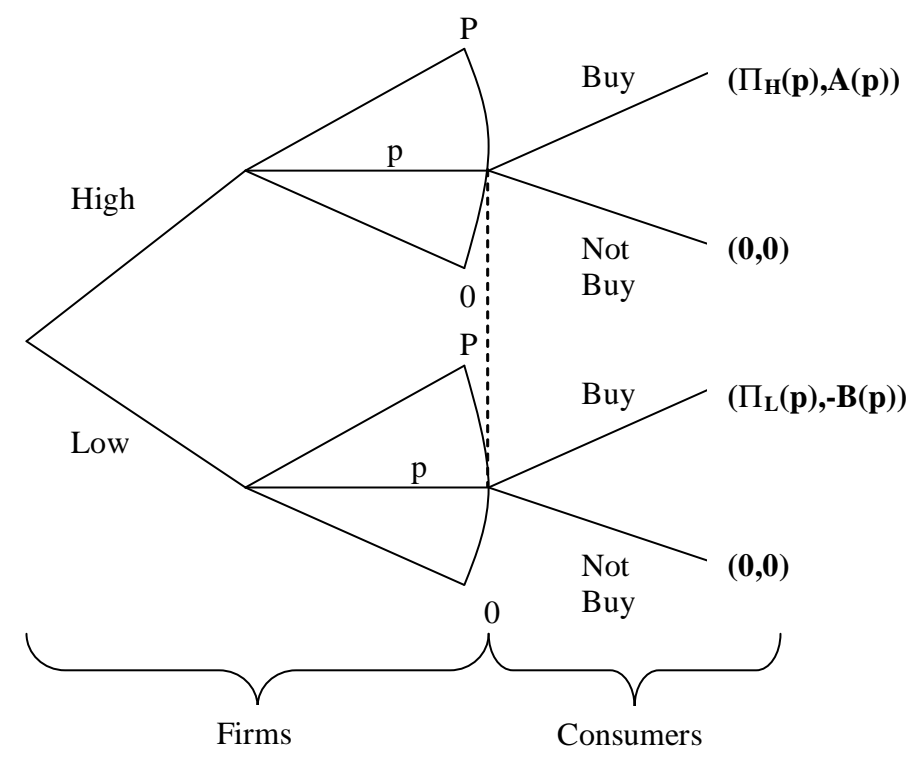

Figure 1: Interactions between a firm and consumers.

\subsection{Entry and equilibrium in the differentiated good}

We assume that firms in the differentiated good sector use a constant returns to scale technology with a marginal cost of production $\psi_{H}$ of the high quality goods and $\psi_{L}<\psi_{H}$ for the low quality goods. There is no fixed cost to be borne by a firm that is present in the industry.

Firms enter sequentially into the industry. The first firm makes a decision on whether to produce a high or low quality product and about the price that it wishes to charge to the consumers. We assume that the firm is obliged to satisfy all demand at the announced price. The firm observes demand of the form $q(p)=Z p^{-\frac{1}{1-\sigma}}$ where $Z=\frac{I \gamma}{\sum_{i} p_{i}^{-\frac{\sigma}{-\sigma}}}$ is considered by the firm to be independent from its decisions. Consumers observe the prices and decide whether to buy or not. The interactions between one firm and the consumers are presented in Figure 1. We analyze the problem as if we were solving a sequential game by backward induction and concentrate on interesting outcomes with positive production. Consumers do not want to buy a faulty product; we assume that even if they engage in a recall of a low quality product and obtain a refund, they would still be observing a negative payoff $-B(p)$. Hence, they will want to ensure that at the price quoted by the firm the company has an incentive to sell a high quality product. The consumers require that the following incentive compatibility constraint holds at a price at which they are willing to buy:

$$
\Pi_{H} \geq \Pi_{L}
$$


We can substitute for profits at a set price $p$

$$
\begin{gathered}
\Pi_{H}=\left(p-\psi_{H}\right) q(p) \\
\Pi_{L}=p q(p)-\psi_{L} q(p)-\frac{(q(p))^{\beta}}{(q(p))^{\beta}+\alpha^{\beta}} \varpi q(p)
\end{gathered}
$$

For the incentive compatibility condition (5) to hold, it must be true that

$$
q(p) \geq\left(\frac{\psi_{H}-\psi_{L}}{\varpi+\psi_{L}-\psi_{H}}\right)^{\frac{1}{\beta}} \alpha
$$

As the firm has to set an incentive compatible price $p_{I C}$, observing the demand it is facing, it knows that for consumers to buy it needs to set a price at most of

$$
\bar{p}_{I C} \leq\left(\frac{Z}{\alpha}\right)^{(1-\sigma)}\left(\frac{\psi_{H}-\psi_{L}}{\varpi+\psi_{L}-\psi_{H}}\right)^{-\frac{1-\sigma}{\beta}}
$$

The incentive compatible price must be above $\psi_{H}$, the cost of the high quality good for the firms to want to actually produce. Consumers are thus going to accept any price which fulfills the criterion (9) and is greater or equal to $\psi_{H}$. If the profit maximizing price of the high quality production without the quality assurance problem is out of the bounds $\left[\psi_{H}, \bar{p}_{I C}\right]$ the firm wishes to charge the highest price that is incentive compatible as only then consumers are going to buy.

If there are positive profits in this industry, i.e. when $\bar{p}_{I C}>\psi_{H}$, then more firms wish to enter. With many firms in the market we cannot capture the monopolistic competition between firms in a rigorous game-theoretic framework, but we can discuss how the interactions between firms and consumers take place. We can think of them as if firms were making simultaneously decisions about quality and prices without taking into consideration the effect of other firms' actions on their payoffs and the effect of their actions on other firms' behavior. Consumers simultaneously evaluate the prices posted by firms and make the purchasing decisions.

Each additional firm that enters exerts a negative externality on firms already in the sector as the demand for their variety falls at any price they might have charged before. This means that the maximal price that they can charge and credibly sell their goods $\bar{p}_{I C}$ has to fall. Hence, as the number of firms in the industry increases, $\bar{p}_{I C} \rightarrow \psi_{H}$. In the free entry equilibrium with zero profits it must be then that the price charged by monopolistically competitive firms is equal to the unit production cost.

The equilibrium in this market is therefore characterized as follows:

- firms maximize profits by charging an incentive compatible price $p^{*}=\bar{p}_{I C}=\psi_{H}$ and providing high quality products. 
- consumers maximize utility given their budget constraint

- the homogenous and differentiated good markets clear

- factor and product markets clear

- the incentive compatibility constraints bind ${ }^{6}: \Pi_{H}=\Pi_{L}$.

We find using (9), the definition of $Z$ and noting that profits are zero while wage income $=L$, the number of firms in this economy

$$
N=\frac{L \gamma}{\alpha}\left(\psi_{H}\right)^{-1}\left(\frac{\psi_{H}-\psi_{L}}{\varpi+\psi_{L}-\psi_{H}}\right)^{-\frac{1}{\beta}}
$$

Thus the number of firms in the industry that are selling high quality depends linearly on the size of the market, $L .^{7}$ The equilibrium quantity sold by each firm $q\left(p^{*}\right)$ remains constant as the size of the economy increases. It is the number of firms, $N$, that adjusts. ${ }^{8}$ Potential additional entrants would not be able to quote an incentive compatible price that would be above $\psi_{H}$. Viewed from another perspective, they cannot capture a market share that would allow them to credibly produce the high quality good.

Here we have the firms not earning any profit, so that in equilibrium $p^{*}=\psi_{H}$ as in a perfectly competitive sector with constant returns to scale production functions. The firms here effectively have a decreasing returns to scale technology in producing the low quality good: as they want to sell more of it on the market, the more difficult it is for them as the higher the chances are that consumers are going to find out that the good is of poor quality, demanding a return of money. This means that as a higher quantity is produced, the firm has higher incentives to produce high quality products. We can also rewrite condition (10) and interpret it as if there was a minimum market size requirement for the production of the high quality good in this economy. We can understand thus why firms often boast while advertising about the number of customers that "trusted" their products as a signal "guaranteeing" quality.

We obtain thus entry of a finite number of firms into an industry with monopolistic competition that does not rely on the existence of sunk costs of entry, contrary to the models of for example Allen (1984) or Farrell (1986). The barrier here comes from the off-equilibrium firm behavior and the fact that it is becomes harder to sell a higher quantity of low quality products undetected. We can have an industrial structure with a finite number of firms no matter what are the scale properties of the production functions of the firms in question. Note that the average costs of the firms of producing the high quality product are not affected in any way by the scale of production, the size of the market, or the number of producing firms present. There are no increasing returns in

\footnotetext{
${ }^{6}$ We treat $N$ as large and as a continuous variable.

${ }^{7} \mathrm{We}$ are, as noted before, interested in equilibria with positive production. In principle many more firms than indicated in equation (10) could enter, charge positive prices and consumers would not buy.

${ }^{8}$ Hence we have adjustments along the extensive and not on the intensive margin.
} 
the production technology. The allocations in the equilibrium with no default in an industry here may, however, look exactly the same as in an equilibrium that one can obtain for example when there are sunk costs of entry into the industry or fixed costs of production.

\section{The open economy}

We assume now that there are two countries which are allowed to trade with one another. We will denote the subindexes pertaining to a country by $i$ and $j$. With international trade, consumers in both markets place orders with firms that are going to be active in both or in either of the markets. As in the closed economy, they will want to buy differentiated products of high quality.

\subsection{Consumers and firms}

The utility function of a consumer in country $i$ is now

$$
U_{i}=\left(\sum_{j} \sum_{k}\left(c_{i, j, k} s_{i, j, k}\right)^{\sigma}\right)^{\frac{\gamma}{\sigma}}\left(c_{0, i}\right)^{1-\gamma}
$$

where $c_{i, j, k}$ denotes the consumption in country $i$ of variety $k$ from country $j$ and $s_{i, j, k}=1$ indicates whether it is of high quality or not. The utility maximization problem on the side of the consumer in country $i$ leads to the following demand for the representative differentiated good of high quality from country $j$ and for homogenous products ${ }^{9}$ :

$$
\begin{gathered}
c_{i, j, k}=\frac{I_{i}}{L_{i}} \frac{\gamma}{P_{i}}\left(p_{i, j, k}\right)^{-\frac{1}{1-\sigma}} \\
c_{0, i}=\frac{I_{i}}{L_{i}} \frac{(1-\gamma)}{p_{0, i}}
\end{gathered}
$$

where $P_{i}=\sum_{j} \sum_{k}\left(p_{i, j, k}\right)^{\frac{\sigma}{1-\sigma}}$ is the differentiated good price index in country $i, p_{i, j, k}$ is the price of a high quality variety $k$ from country $j$ in country $i$ and $p_{0, i}$ is the price of the homogenous good in country $i$.

In the perfectly competitive homogenous good sector, as in the closed economy, there are many active firms with constant returns to scale production functions and there are no costs of entry into that sector. These firms use local labor. Denote the employment in the whole homogenous good industry in country $i$ by $L_{0, i}$. Consumers are indifferent about the country of origin of the homogenous good.

\footnotetext{
${ }^{9}$ In what follows if the prices do not have an explicitly stated index $L$ to represent low quality products, we will consider them to represent high quality.
} 
There is an iceberg trade cost in international trade of differentiated goods but there are no fixed costs of entering the foreign market. We assume that only a fraction $\tau^{-1} \leq 1$ of output that is shipped abroad survives transit. We assume that firms are setting one factory price and the labor requirement to produce a high quality good is $\psi_{H}=1$.

Consumers in each country now face two types of firms - home and foreign - that can enter into the differentiated good industry. For trade to arise it is crucial that firms choose only one location for production and serve the foreign market through exports. Consumers perceive goods coming from different plants (in different countries) as having potentially different qualities and firms cannot credibly pre-commit to choosing the same product quality in all plants they own. ${ }^{10}$ So if a firm has two plant locations, then the quality choice problem must be made for each plant separately. Consumers will check that the incentive compatibility constraint is satisfied for the plant from which the goods will come from before placing their orders. Then, as we argue below, firms will have incentives to choose only one plant location so as to concentrate production to satisfy the incentive compatibility condition and so that their goods are ordered by the consumers. This gives rise to intra-industry trade in differentiated goods.

Suppose that firms locate only in one country and serves the foreign country through exports. If consumers in any country find out a given variety is of low quality, this will be widely publicized and all units of the variety will be recalled regardless of where they are being sold since they come from the same manufacturing plant. ${ }^{11}$ We assume that handling the recall from the foreign country costs the firm $\tau \varpi$ per unit of the recalled good. Consider a firm from country $i$. This firm's profits in the case of cheating are

$\Pi_{L}=\left(p_{i, i}-\psi_{L}\right)\left(q_{i, i}\left(p_{i, i}\right)+\tau q_{j, i}\left(\tau p_{i, i}\right)\right)-\frac{\left(q_{i, i}\left(p_{i, i}\right)+q_{j, i}\left(\tau p_{i, i}\right)\right)^{\beta}}{\left(q_{i, i}\left(p_{i, i}\right)+q_{j, i}\left(\tau p_{i, i}\right)\right)^{\beta}+\alpha^{\beta}} \varpi\left(q_{i, i}\left(p_{i, i}\right)+\tau q_{j, i}\left(\tau p_{i, i}\right)\right)$

where the first term describes the profits from cheating on the production of $\left(q_{i, i}\left(p_{i, i}\right)+\tau q_{j, i}\left(\tau p_{i, i}\right)\right)$

\footnotetext{
${ }^{10}$ Examples of this abound, for example in Eastern Europe, where locally produced goods even of the same brand (washing powder or cars) are often treated by consumers as different qualities from those available from West European country plants. See also accounts of managers as in Financial Times (FT.com) (5 October 2006). The chief executive of the company Henkel names as one of the three strategies of serving markets.globally "A local product with a global brand" where under the same brand (Persil) washing powder of different quality is sold in different markets.

${ }^{11}$ We assume thus perfect information flows between markets. This is not a necessity, but it greatly streamlines the exposition.

It is a good approximation in today's world. Consider the worldwide uproar and press campaign after the discovery of faulty Chinese products: food, toys, toothpaste, tyres, quads, cycles. See for a series of stories in The Wall Street Journal (14 May 2007, 24 May 2007, 06 June 2007 or 26 July 2007) where these goods received close scrutiny.

RAPEX is an institution that instantaneously spreads of information about faulty products once they are discovered in one of the countries of the European Union (see reports at http://ec.europa.eu/consumers/dyna/rapex/rapex_archives_en.cfm).

The consumer uproar followed by the images shown on YouTube prompted Dell in 2006 to recall immediately $4 \mathrm{~m}$ laptop batteries that could catch fire (Financial Times, 15 August 2006).
} 
units and $\frac{\left(q_{i, i}\left(p_{i, i}\right)+q_{j, i}\left(\tau p_{i, i}\right)\right)^{\beta}}{\left(q_{i, i}\left(p_{i, i}\right)+q_{j, i}\left(\tau p_{i, i}\right)\right)^{\beta}+\alpha^{\beta}}$ is the probability that there is a recall following the sale of $\left(q_{i, i}+q_{j, i}\right)$ units in both markets.

The condition for providing high quality that the consumers inspect for a firm from country $i$ is now ${ }^{12}$ :

$$
q_{i, i}\left(p_{i, i}\right)+q_{j, i}\left(\tau p_{i, i}\right) \geq\left(\frac{\left(\psi_{H}-\psi_{L}\right)}{\left(\psi_{L}+\varpi-\psi_{H}\right)}\right)^{\frac{1}{\beta}} \alpha
$$

which can be rewritten as a condition on the mill price that consumers are going to inspect

$$
\bar{p}_{I C} \leq\left(\frac{Z_{i}+\tau^{-\frac{1}{1-\sigma}} Z_{j}}{\alpha}\right)^{1-\sigma}\left(\frac{\left(\psi_{H}-\psi_{L}\right)}{\left(\psi_{L}+\varpi-\psi_{H}\right)}\right)^{-\frac{1-\sigma}{\beta}}
$$

where $Z_{i}=\frac{I_{i} \gamma}{P_{i}}$ and $Z_{j}=\frac{I_{j} \gamma}{P_{j}}$.

If firms were to split production and serve only the local market from each plant location, then consumers in each country require that the incentive compatibility constraint given by () holds for each plant. With free entry prices will be bid down to marginal cost and the inceintive compatibility condition will hold with strict equality : $q_{i, i}\left(p_{i, i}\right)=q(p)=\left(\frac{\psi_{H}-\psi_{L}}{\varpi+\psi_{L}-\psi_{H}}\right)^{\frac{1}{\beta}} \alpha$.Suppose then that a firm tries to concentrate production and serves foreign market through exports, condition (15) would be slack. Therefore it could charge prices above the marginal cost of production and would be earning positive profits while still fulfilling the incentive compatibility condition. In a free entry equilibrium it will have to be the case that there are zero profits for firms that concentratre their production and hence $\bar{p}_{I C}=\psi_{H}$ and the incentive compatibility conditions for exporting firms will be binding. Therefore, condition (15) will hold with strict equality. This however, also implies that firms that split production will not be incentive compatible and hence no firms will want to split production. The intuition for this result is that concentrating production makes detection of default products easier since there is a larger quantity of products being sold from the same plant and hence firms have less incentives to produce low quality products compared to a firm which produces only for the local market. Consumers know this and will not purchase from a firm that produces only for the local market.

\footnotetext{
${ }^{12}$ From a firms' point of view, selling to only one market is a dominated strategy as with the Dixit-Stilgitz preferences you get positive demand of a high quality good in the other country with prices converging to infinity that can cover even arbitrarily high trade costs. Therefore any firm that enters the differentiated good sector will engage in international trade.

Moreover, a firm that wishes to export its goods abroad has it easier to fulfill the incentive compatibility constraint than a one that wants to sell only to the home market. This is because the expected sales of low quality goods are a nonlinear function of the quantity sold and with sales in multiple markets an exporting firm can sell more goods which helps it to satisfy the global constraint on the size of required sales. If the expected sales were linear, more sales (also abroad) would not affect the incentives of firms at all.
} 
It will be easier for us to work, however, with condition (15) written as

$$
q_{i, i}\left(p_{i, i}\right)+q_{j, i}\left(\tau p_{i, i}\right)=F
$$

where $F$ is a constant depending on parameter values $\gamma, \sigma, \psi_{H}, \psi_{L}, \varpi$ and $\beta$. From the point of view of firms from country $j$ the condition is

$$
q_{j, j}\left(p_{j, j}\right)+q_{i, j}\left(\tau p_{j, j}\right)=F
$$

Requirements (16) and (17) are such that firms in the differentiated sector has to be able to find a market that is large enough for their goods.

\subsection{Equilibrium}

We solve for an equilibrium where $L_{0, i}>0$ and $L_{0, j}>0$ so that both countries produce the homogenous good and hence there is factor price equalization between the two countries. The factor allocation in country $i$ is $L_{i}=L_{0, i}+N_{i} L_{i, k}$ where $N_{i}$ is the number of firms from country $i$ in the differentiated sector and $L_{i, k}$ is labor employed by firm $k$. Income in country $i$ is $I_{i}=w_{i} L_{i}$ since profit of firms is zero. If the homogenous good is produced in both countries and there are no trade barriers on international trade in the homogenous good sector it must be true that $p_{0}=p_{0, i}=p_{0, j}$ and that the wages between countries are equalized $w_{i}=w_{j}$ and so we have factor price equalization. We set $w_{i}=1$. The global supply of the homogenous good must equal the global demand $\sum L_{0, i}=\frac{(1-\gamma)}{p_{0}} \sum I_{i}$. Balanced trade requires that expenditures are equal to income and from the perspective of country $i$ it is $I_{i}(1-\gamma)+N_{i} p_{i, i} q_{i, i}+N_{j} p_{i, j} q_{i, j}=L_{0, i}$.

We can rewrite (16) and (17) as

$$
\begin{aligned}
& \Phi=\frac{L_{i}}{N_{i}+N_{j}(\tau)^{-\frac{\sigma}{1-\sigma}}}+(\tau)^{-\frac{1}{1-\sigma}} \frac{L_{j}}{N_{i}(\tau)^{-\frac{\sigma}{1-\sigma}}+N_{j}} \\
& \Phi=\frac{L_{j}}{N_{i}(\tau)^{-\frac{\sigma}{1-\sigma}}+N_{j}}+(\tau)^{-\frac{1}{1-\sigma}} \frac{L_{i}}{N_{i}+N_{j}(\tau)^{-\frac{\sigma}{1-\sigma}}}
\end{aligned}
$$

where $\Phi=\frac{F}{\gamma}$. An equilibrium number of firms $N_{i}$ and $N_{j}$ can be found by solving this system of equations.

We focus on the interior equilibrium where the differentiated good industry exists in both coun- 
tries. We solve the equations (18) and (19) to obtain

$$
\begin{aligned}
& N_{i}=\frac{\left(1+(\tau)^{-\frac{1}{1-\sigma}}\right)}{\Phi\left(1-(\tau)^{-\frac{2 \sigma}{1-\sigma}}\right)}\left(L_{i}-L_{j}(\tau)^{-\frac{\sigma}{1-\sigma}}\right) \\
& N_{j}=\frac{\left(1+(\tau)^{-\frac{1}{1-\sigma}}\right)}{\Phi\left(1-(\tau)^{-\frac{2 \sigma}{1-\sigma}}\right)}\left(L_{j}-L_{i}(\tau)^{-\frac{\sigma}{1-\sigma}}\right)
\end{aligned}
$$

If $L_{i}=L_{j}$ the solution is such that both countries have the same number of active firms. From equations (20) and (21) we conclude that more firms are going to be active in the larger economy.

Without iceberg trade costs (i.e. $\tau=1$ ) and no problems in transmitting information about the detection of low quality products in the integrated market the number of varieties that can be sustained with two symmetric countries is twice that of the amount that exists in each country in autarky. International trade in the differentiated good is thus beneficial for symmetric countries as consumers can enjoy more high quality varieties in a combined larger market.

We provide hence a new explanation for intra-industry trade. Quality assurance requires that production is concentrated in one location only. Firms cannot profitably split production as consumers know that the products from a given plant are of the same quality but rightly perceive products coming from different plants as being of potentially different quality. Moreover, it is easier, ceteris paribus, for a firm selling into many markets from one location to fulfill the incentive compatibility conditions. Facing a larger market, a firm producing low quality does not benefit as much as a firm producing high quality because it is easier to detect low quality products with higher sales and the foregone expected revenue from providing low quality instead of high quality is higher. This implies that firms will want to serve international markets by producing at one location and with a larger market, the equilibrium number of firms increases. The gains from trade can be traced thus from increased variety of high quality differentiated goods that consumers may enjoy in an open economy. Intra-industry trade is driven in our model by product differentiation and the need for quality assurance and not by the existence of increasing returns to scale in production as in Krugman (1980) or through Ricardian motives for trade as in Davis (1995).

Moreover, we conjecture that if foreign consumers tested the goods in different circumstances or had better detection of faulty products and a strong response of consumers to the presence of low quality goods in the market, the minimum market size requirement may fall. We could think here about the additional scrutiny that foreign goods receive either from authorities, businesses or consumers (for example Chinese pet food or toothpaste). These widely publicized revelations may benefit also consumers by eradicating cheating firms from the local market as well once the faulty goods are discovered abroad. 


\subsection{The existence of the home market effect}

We investigate whether the home market effect - the tendency of differentiated good firms to concentrate in the country with the larger demand making it a net exporter of these products - can hold in our model.

Proposition 1 The larger country produces more varieties and is a net exporter of the differentiated goods.

Proof. See appendix.

The striking finding is that the home market effect exists in our monopolistically competitive model with constant returns to scale production functions and no entry costs into the industry. Furthermore, we have firms earning zero profits and pricing at the marginal cost. Firms want to move to the location with higher demand because it is easier for them to obtain higher revenues and stronger reputation (that would also render the company credible in selling high quality goods into other markets as well) by selling directly to this market to avoid the trade costs that reduce sales. Looking at it another way, starting from a proportional equilibrium where the share of differentiated goods firms in each country is proportional to its share of world demand, firms in the larger market will have larger sales because of the lower trade costs in accessing the two markets. Their incentive compatibility constraint is thus slack if the one for firms located in the smaller market is binding. Additional firms can thus enter in the large country without violating the incentive compatibility constraint. The larger country will thus have a larger than proportional share of differentiated good firms giving rise to the home market effect. This urge to concentrate production for quality assurance reasons exists no matter what is the production function of the firm. Our model can thus validate the empirical results about the presence of the home market effect in constant returns to scale industries.

\section{Repeated interactions and the importance of time flow in trade}

In reality, incentives for firms to produce high quality goods may be provided also through repeated purchases. If a firm does not deliver high quality in a given period, consumers may punish the firm by buying nothing in the following periods. Moreover, consumers may not possess costlessly all the required information about the cost structures of firms to make thoughtful purchasing decisions. Firms may also not meet all demand at a given price (i.e. the quantity may be a strategic variable). Here, we provide a different model where we introduce retailers and repeated 
interactions between firms and retailers; yet, as in the former model there are no increasing returns in production.

\subsection{Consumption, Production and Entry}

Suppose that the world lasts infinitely many periods and agents (firms) discount the future with a rate of discount $\delta<1$. Consumer preferences are the same as in the preceding model but we assume that the elasticity of substitution over the different varieties in the utility function is now an increasing function of the number of varieties consumed. More specifically we assume that $\sigma^{\prime}(N)>0$ and $\lim _{N \rightarrow \infty} \sigma(N)=1 .^{13}$ The homogenous good industry setup is the same as before. There is again a quality assurance problem in the production of the differentiated good with a modified entry structure as follows.

The differentiated goods are sold through retailers that can place supply orders with producers. Retailers know the technology (and hence the cost structures) of firms. Retailing is a perfectly competitive sector. Retailers coordinate on the choice of differentiated good firms that they are going to serve. Once they do this, they just sell the products that these firms deliver. The retailers bear any costs of a potential recall of goods. Thus, they have an incentive to make sure the firms are providing goods of a quality that is high.

Entry into the industry proceeds as follows: first the retailers select the firms whose products they are going to carry. Once retailers place an order, a firm acts as in a monopolistic competitive industry: it forms an expectation of the demand that it faces and it ignores the effect of its pricing decisions on the overall pricing level and global income. The firm chooses the quality, sets a price and produces after comparing the benefits of manufacturing high and low quality.

Consumers have no information about the cost structures of firms. They believe that once the good is on the shelf it is of high quality. ${ }^{14}$ Hence the prices quoted when the firm is producing low and high quality may be different and we denote them as $p_{L}$ and $p_{H}$ respectively. ${ }^{15}$ After the firm produces, deliveries take place and consumers buy. If low quality products are discovered, retailers cancel the orders with the firms that supplied low quality in future periods. ${ }^{16}$

\footnotetext{
${ }^{13}$ Note that this assumption implies that effectively the markup over cost charged by monopolistic firms in equilibrium is a declining function of the number of firms in the industry.

${ }^{14}$ They will be correct in equilibrium.

${ }^{15} \mathrm{We}$ focus here solely on the repeated provision of incentives.

${ }^{16}$ Retailers could in theory introduce other methods of quality assurance. They could perform sampling of products, which is costly and results in a statistical measure of quality (for example of faulty products) that becomes better with the higher number of units sampled. The higher thus the amount of sales, the lower the probability of presenting consumers with low-quality goods, as in this model. Retailers, carrying thousands of different products, often cannot use sampling effectively (New York Times, 15 August 2007). Moreover, with truly experience goods where the quality of a product can be learned only after considerable usage, the retailers may be helpless in detecting low quality even if they use sampling.

In many countries (for example, Germany) retailers (and importers) are legally liable to consumers in case there is
} 


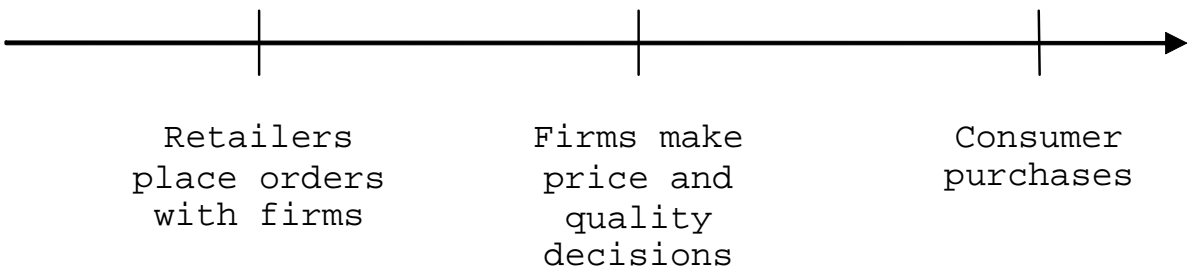

Figure 2: The timing of events within a period

The timing of events is presented in Figure 2.

Retailers want to make sure that each firm in this sector has the following incentive compatibility condition holding where the left hand side represent the profits from high quality good provision and the right hand side the profits from one-period deviation (cheating):

$$
\frac{\left(p_{H}-\psi_{H}\right)}{1-\delta} q\left(p_{H}\right) \geq\left(p_{L}-\psi_{L}\right) q\left(p_{L}\right)
$$

Since firms that sell a low quality differentiated good bear lower costs than when they would offer high quality (and the punishment for low quality provision is imperfect) a zero profit condition for firm entry is now incompatible with high quality provision. How can thus high quality products be supplied in an equilibrium? Following the analysis in the literature started by Klein and Leffler (1981) firms need to be offered rents so that they will want to offer high quality. In the context of our model this means that retailers can deny trading with but a few firms to make sure that these obtain profits that are high enough.

The firm's maximization problem when it decides to produce high quality is $\max _{p_{H}}\left(p_{H}-\psi_{H}\right) q\left(p_{H}\right)$ or $\max _{p_{H}}\left(p_{H}-\psi_{H}\right) Z\left(p_{H}\right)^{-\frac{1}{1-\sigma(N)}}$ where $Z$ is treated by the firm as exogenous. The firms would charge an optimal price $p_{H}^{*}=\frac{\psi_{H}}{\sigma(N)}$. Analogously we can find for the case when the firm would consider producing a low quality product $p_{L}^{*}=\frac{\psi_{L}}{\sigma(N)}$. After substituting for the optimal prices into (22) and some manipulations we get

$$
\sigma(N) \leq \frac{\ln (1-\delta)}{\ln \left(\psi_{L}\right)-\ln \left(\psi_{H}\right)+\ln (1-\delta)}
$$

This condition means that firms are going to provide high quality goods whenever they will observe a markup that is high enough or in other words have a strong market power (they observe a substitution between differentiated goods that is low enough). As $\sigma(N)$ is an increasing function of the number of firms in the differentiated good sector, this condition pins down the number of firms producing high quality in the differentiated good sector.

a product recall. 
As a result, retailers do not place orders with too many firms as they know that then these firms will provide low quality products. An increase in competition in this market lowers the profits of high quality firms relative to the low quality firms and hence increases the firms' incentives to cheat on product quality. ${ }^{17}$ Thus, the retailers carry only "brands" that they (and consumers as well) expect to be high quality products and for which consumers are willing to pay a premium. This has a flavor of the relationship between the severity of the moral hazard problem and competition as for example discussed in Schmidt (1997) where increased competition in the market may exacerbate the agency problem and cause the delivery of proper incentives to be more costly. A similar issue was raised in the context of the banking sector by Hellmann et al. (2000) who argued that increased competition in banking may increase moral hazard and lead banks to make less prudent decisions. ${ }^{18}$

The number of firms in equilibrium here does not depend on the market size, but only on the discount factor $\delta$ and the costs of high and low quality provision $\psi_{H}$ and $\psi_{L}$.

\subsection{International trade}

Suppose now that there are two countries where consumers have the same preferences over goods. There are iceberg transport costs of trade $\tau$ in the differentiated good but no trade costs in the homogenous good. Assume for the moment that the firms in the differentiated sector need to locate in one country to produce. For example, consumers and retailers may consider the production from another factory in another country as another variety. Then the incentive compatibility condition for the firm is

$$
\frac{\left(p_{H}-\psi_{H}\right)}{1-\delta} q_{i, i}\left(p_{H}\right)+\tau \frac{\left(p_{H}-\psi_{H}\right)}{1-\delta} q_{j, i}\left(\tau p_{H}\right) \geq\left(p_{L}-\psi_{L}\right) q_{i, i}\left(p_{L}\right)+\tau\left(p_{L}-\psi_{L}\right) q_{j, i}\left(\tau p_{L}\right)
$$

which leads to a condition

$$
\sigma(N) \leq \frac{\ln (1-\delta)}{\ln \left(\psi_{L}\right)-\ln \left(\psi_{H}\right)+\ln (1-\delta)}
$$

which is the same as (23). The number of firms in the combined market is exactly the same as in the closed economy. We should not be surprised as the result is in the spirit of Bernheim and Whinston (1990) translated to our context: the presence of a firm in more markets with linear return functions does not increase its incentives to provide high quality products. Neither of the

\footnotetext{
${ }^{17}$ An expert claimed after deficient quality due to cheap and toxic materials was found in toys in a series of recalls in 2007: "there is something to be said about the pressure that American and European and multinational companies put on Chinese companies to supply cheap products. The operating margins are razor thin, so you really should not be surprised that there is pressure to cut corners." (New York Times, 15 August 2007).

${ }^{18}$ Banking has the help of regulators in order to assure that a limited number of banks enjoy a stream of profits that makes them credible. Apart from that, there is also a minimum size requirement for entrants into the banking sector in many countries.
} 
countries gains from trade as the number of varieties remains constant and the consumers of each country pay more for varieties of firms that locate in the other country.

\subsection{Concentration of production and the time aspect of trade}

Some might be uncomfortable with the assumption that a firm has to locate in one country to produce its variety. Indeed, if both retailers and consumers would treat for example toys or children apparel from a French or a Chinese plant of the same firm in the same way, then firms would have an incentive to split production and produce in both locations serving local markets only to avoid trade costs, so that international trade would be zero (and the number of firms and varieties would be the same as in autarky). In each country, the firm will face the incentive compatibility conditions

$$
\begin{aligned}
& \frac{\left(p_{H}-\psi_{H}\right)}{1-\delta} q_{i, i}\left(p_{H}\right) \geq\left(p_{L}-\psi_{L}\right) q_{i, i}\left(p_{L}\right) \\
& \frac{\left(p_{H}-\psi_{H}\right)}{1-\delta} q_{j, i}\left(p_{H}\right) \geq\left(p_{L}-\psi_{L}\right) q_{j, i}\left(p_{L}\right)
\end{aligned}
$$

which imply a global incentive compatibility condition for providing high quality ${ }^{19}$ :

$$
\frac{\left(p_{H}-\psi_{H}\right)}{1-\delta} q_{i, i}\left(p_{H}\right)+\frac{\left(p_{H}-\psi_{H}\right)}{1-\delta} q_{j, i}\left(p_{H}\right) \geq\left(p_{L}-\psi_{L}\right) q_{i, i}\left(p_{L}\right)+\left(p_{L}-\psi_{L}\right) q_{j, i}\left(p_{L}\right)
$$

which leads after substitution to the condition

$$
\sigma(N) \leq \frac{\ln (1-\delta)}{\ln \left(\psi_{L}\right)-\ln \left(\psi_{H}\right)+\ln (1-\delta)}
$$

the same as before in (23) and (28) with the same number of firms in equilibrium. As profits from splitting production would be higher, firms would be willing to do so; retailers and consumers would accept. The welfare with production in different locations would be exactly equal to the one under autarky.

There is, however, another aspect of international trade that is often sidestepped ${ }^{20}:$ it takes time for goods to travel from one location to the other. Consider that within each period it takes time for the goods to reach the other market so that domestic consumers would have already purchased and known the quality of the products before foreign consumers start purchasing the products. We assume that information will spread such that a fraction of the foreign consumers $(1-\rho)$ already know that the good is faulty and hence will not purchase if the firm cheated on quality. Hence

\footnotetext{
${ }^{19}$ Alternatively, after eliminating the quantities, they boil down to the same condition.

${ }^{20}$ But see recently Harrigan and Venables (2006).
} 
foreign sales will be lower than if the high quality good were offered at the same price. ${ }^{21} \mathrm{We}$ can interpret the parameter $\rho$ in many ways; if a product is found faulty in the domestic market, it can capture the strength and speed of implementation of a foreign official ban on the good, the cancelled orders by retailers (who can be better informed than consumers are) or the willingness of the foreign consumers to buy the product once the information about low quality leaks out from the producer country. Then, the incentive compatibility of a firm producing from one location will be

$$
\frac{\left(p_{H}-\psi_{H}\right)}{1-\delta} q_{i, i}\left(p_{H}\right)+\tau \frac{\left(p_{H}-\psi_{H}\right)}{1-\delta} q_{j, i}\left(\tau p_{H}\right)>\left(p_{L}-\psi_{L}\right) q_{i, i}\left(p_{L}\right)+\tau \rho\left(p_{L}-\psi_{L}\right) q_{j, i}\left(\tau p_{L}\right)
$$

Now, suppose that condition (28) is binding. We show that for $\rho<1$ condition (30) will then hold with slack for the same number of firms present in the market.

Proposition 2 Suppose that the condition (28) holds. Then condition (30) is slack.

Proof. See appendix.

Proposition (2) implies that if there is a time lag in shipment and that some foreign customers receive news about the (bad) quality of the product before purchase, then firms that concentrate production in one location will have more incentives to produce high quality products than firms that split production. ${ }^{22}$ This is because by concentrating production, producing low quality will be more heavily penalized by reduced foreign sales. If production is split, both set of consumers will learn about the quality at the same time and hence low quality producers will not suffer any reduced sales compared to high quality producers. It follows then that the retailers could accept to carry more firms' products when they concentrate their production than in the case when firms split production without violating condition (30). ${ }^{23}$ Hence the global number of varieties that can be

\footnotetext{
${ }^{21}$ This feature could pertain particularly to such goods as food where the quality of a product can be found out quickly relatively to the shipping time.

For example, the news about mozarella cheese contamination with dioxines first spread in Italy; immediately South Korea banned sales of the cheese even without an official communication from the Italian authorities but "after foreign media reported that high levels of dioxin were found in some samples in Italy" (see Korea Times, 23 March 2008). Japan soon followed suit.

Another example is the discovery of a mad cow disease case in the US on 23rd December 2003. Immediately 16 countries, including the largest U.S. beef importers Japan and South Korea, issued a ban on imports of U.S. beef (see Financial Times FT.com, 23 December 2003). The removal of the ban in Korea due to a free trade agreement with the US sparked mass demonstrations a couple of years later.

${ }^{22}$ In this context, we can rationalize the claim by firms in advertising of how many different markets they serve and why they boast that they are in fact exporting. Of course this may be also for different reasons; in Eastern European countries, exporting firms often provided also higher quality goods. The fact that they were able to fulfill foreign standards was a signal of high quality to domestic consumers.

${ }^{23}$ A retailer would want to carry additional products if this were the only retailer to serve the firm and capture some rents from the relationship. But then, all retailers would want to include the products of the new entrants as long as it would have the incentives to produce high quality products. With more firms in the market, any non-exporters goods would no longer be accepted as they would not have the incentives to provide high quality goods.
} 
sustained is higher than in the case of splitting production or in autarky. There might be therefore a gain from concentrating production and hence a demand by retailers that each variety is delivered only from one country. Whether welfare is higher or not from international trade in this case depends on the behavior of $\sigma(N)$ with $N$. If the increase of $N$ is strong with trade integration then concentrating production and serving the foreign markets by exports would be welfare improving over autarky. The welfare gain would come not only because of the increased number of varieties available in the market, but also because of lower prices to customers as firms would charge lower markups (as $\sigma(N)$ would increase). Therefore, we can observe intra-industry trade that may be welfare improving because of quality assurance purposes. ${ }^{24}$

\subsection{The home market effect}

What can we say about the home market effect in the context of this model? When a firm is considering locating in a particular country, it is contemplating the profits that it can get from producing from either location. We can rewrite the profits from locating in country $i$ as

$$
\begin{aligned}
\Pi_{i} & =\left(p_{H}-\psi_{H}\right) q_{i, i}\left(p_{H}\right)+\tau\left(p_{H}-\psi_{H}\right) q_{j, i}\left(\tau p_{H}\right) \\
& =(1-\sigma(N))\left(\frac{\psi_{H}}{\sigma(N)}\right)^{-\frac{\sigma(N)}{1-\sigma(N)}}\left(Z_{i}+\tau^{-\frac{\sigma(N)}{1-\sigma(N)}} Z_{j}\right)
\end{aligned}
$$

and in country $j$

$$
\Pi_{j}=(1-\sigma(N))\left(\frac{\psi_{H}}{\sigma(N)}\right)^{-\frac{\sigma(N)}{1-\sigma(N)}}\left(Z_{j}+\tau^{-\frac{\sigma(N)}{1-\sigma(N)}} Z_{i}\right)
$$

For there to be a positive number of firms located in both countries (and the firms being indifferent between moving) it is required that the profits in both countries are equal. Substituting for $Z_{i}$ and $Z_{j}$ we require that

$$
\frac{L_{i}}{N_{i}+N_{j} \tau^{-\frac{\sigma(N)}{1-\sigma(N)}}}=\frac{L_{j}}{N_{i} \tau^{-\frac{\sigma(N)}{1-\sigma(N)}}+N_{j}}
$$

From this, we can find

$$
N_{j}=N_{i} \frac{\left(L_{j}-L_{i} \tau^{-\frac{\sigma(N)}{1-\sigma(N)}}\right)}{\left(L_{i}-\tau^{-\frac{\sigma(N)}{1-\sigma(N)}} L_{j}\right)}
$$

\footnotetext{
${ }^{24}$ The forces present here are similar to those active in a reciprocal dumping model of trade: on the one hand, international trade may increase welfare because there are lower prices, but on the other hand it lowers welfare as there are trade costs that have to be borne when goods cross borders.
} 
If $L_{i}>L_{j}$ we have

$$
\frac{\left(L_{j}-L_{i} \tau^{-\frac{\sigma(N)}{1-\sigma(N)}}\right)}{\left(L_{i}-\tau^{-\frac{\sigma(N)}{1-\sigma(N)}} L_{j}\right)}<1
$$

and then $N_{i}>N_{j}$.

Proposition 3 The home market effect holds.

Proof. See appendix.

Here we notice that the fact that the home market effect holds does not depend on the number of firms active in the market (indeed, we do not solve for the total number of firms $N$ ). It will hold when we assume that consumers perceive each variety coming from each plant as different (so that when the number of firms does not change with the opening of the economy) as in Section 4.2 but also when we introduce time in shipping goods internationally as in Section 4.3 so that the number of varieties present in the market increases with international trade.

\subsection{Discussion}

In this model, the fact that there is a time lag in shipment so that foreign sales are affected once there are bad news coming from the domestic consumers provides a reason for firms to concentrate production in one location which is needed for intra-industry trade to occur. If we assume that products produced in different countries are considered as different varieties, then this assumption is not needed. The incentive compatibility condition fixes the total number of firms that can exist in the free entry equilibrium in the two countries. The presence of transport costs implies that starting from a proportional equilibrium, firms in the larger market will earn higher profits and hence more firms will enter the larger market until profits are equalized. This gives rise to the home market effect without any increasing returns to scale in production. However, there may be no gains from trade unless there is an increase in the number of firms. Increasing returns are thus not necessary to explain neither the home market effect nor the welfare gains from intra-industry international trade. But they may be necessary to ascertain that there are welfare gains from trade at all times!

\section{Conclusions}

In this paper, we derived an endogenous industrial structure based upon the need to provide incentives for firms to produce high quality goods in the absence of perfect information about product quality. We demonstrated that the home market effect can arise under a non increasing returns to scale technology of production. Our result is thus consistent with the empirical finding 
that home market effects are observed for constant returns to scale industries. It also suggests that finding a home market effect in the data may not be sufficient to validate the new trade theory models with increasing returns in production technology.

\section{References}

Allen, Franklin. 1984. 'Reputation and Product Quality.” Rand Journal of Economics, 15(3): 311327.

Antweiler, Werner, and Daniel Trefler. 2002. "Increasing Returns and All That: A View from Trade." American Economic Review, 92(1): 93-119.

Benassy, Jean-Pascal. 1998. "Is There Always Too Little Research in Endogenous Growth With Expanding Product Variety?" European Economic Review, 42(1): 61-69.

Bernheim, Douglas and Michael D. Whinston. 1990. "Multimarket Contact and Collusive Behavior." RAND Journal of Economics, 21: 1-26.

Davis, Donald. 1995. "Intra-industry Trade: A Heckscher-Ohlin-Ricardo Approach.” Journal of International Economics, 39: 201-226.

Davis, Donald. 1998. "The Home Market, Trade, and Industrial Structure." American Economic Review, 88(5): 1264-1276.

Davis, Donald and David E. Weinstein. 1999. "Economic Geography and Regional Production Structure: An Empirical Investigation. European Economic Review, 43: 379-407.

Davis, Donald and David Weinstein. 2003. "Market Access, Economic Geography and Comparative Advantage: an Empirical Test.” Journal of International Economics, 59: 1-23.

Dixit, Avinash and Joseph E. Stiglitz. 1977. "Monopolistic Competition and Optimum Product Diversity." American Economic Review 67: 297-308.

Ethier, Wilfred. 1982. "National and International Returns to Scale in the Modern Theory of International Trade." American Economic Review 72: 389-405.

Farrell Joseph. 1986. "Moral Hazard as an Entry Barrier." Rand Journal of Economics, 17(3): 440-449.

The Financial Times. 2003. "Tests confirm first US case of mad cow disease." 23 December

The Financial Times. 2006. "Brands Stop at the Border," 5 October. 
The Financial Times. 2006. "Dell to Recall 4m Laptop Batteries," 15 August.

The Financial Times. 2007. "Confectioner 'Closed Eyes' to Salmonella Risk," 14 July.

Feenstra, Robert C., James Markusen, and Andrew Rose. 2001. "Using the Gravity Equation to Differentiate Among Alternative Theories of Trade." Canadian Journal of Economics, 34(2): 430447.

Hanson, Gordon, and Chong Xiang. 2004. "The Home Market Effect and Bilateral Trade Patterns." American Economic Review, 94(4):1108-1129.

Harrigan, James, and Anthony Venables. 2006. "Timeliness and Agglomeration." Journal of Urban Economics, 59: 300-316.

Head, Keith, and Thierry Mayer. 2004. "The Empirics of Agglomeration and Trade." In Handbook of Regional and Urban Economics, Vol. 4, eds. Vernon J. Henderson and Jacques-Francois Thisse, Elsevier

Head, Keith, Thierry Mayer, and John Ries. 2002. "On the Pervasiveness of Home Market Effects." Economica, 69: 371-90.

Hellmann, Thomas F., Kevin C. Murdock, and Joseph E. Stiglitz. 2000. "Liberalization, Moral Hazard in Banking, and Prudential Regulation: Are Capital Requirements Enough?" American Economic Review, 90(1): 147-165.

Helpman, Elhanan, and Paul Krugman. 1985. Market Structure and Foreign Trade: Increasing Returns, Imperfect Competition, and the International Economy. Cambridge, MA: MIT Press.

Klein, Benjamin, and Keith B. Leffler. 1981. "The Role of Market Forces in Assuring Contractual Performance.” Journal of Political Economy 89: 615-641.

Korea Times. 2008. ”Korea Bans Italian Mozzarella," 23 March.

Krugman, Paul. 1979. "Increasing Returns, Monopolistic Competition, and International Trade." Journal of International Economics, 9: 469-479.

Krugman, Paul. 1980. "Scale Economies, Product Differentiation and the Pattern of Trade." American Economic Review, 70(5): 950-959.

New York Times. 2007. "Toy Magnets Attract Sales, and Suits," 15 July.

New York Times. 2007. "Mattel Recalls 19 Million Toys Sent From China," 15 August. 
New York Times. 2007. "The Everyman Who Exposed Tainted Toothpaste," 1 October.

Rauch, James. 1999. "Networks Versus Markets in International Trade." Journal of International Economics, 48: 7-35.

Schmidt, Klaus. 1997. "Managerial Incentives and Product Market Competition." Review of Economic Studies, Vol. 64, 191-213.

Shapiro, Carl. 1983. "Premiums for High-Quality Products as Rents to Reputation." Quarterly Journal of Economics, 98: 659-680.

The Wall Street Journal. 2007. "Chinese Pet Food Tricks," 14 May.

The Wall Street Journal. 2007. "FDA Blocks Imports of Chinese Toothpaste," 24 May.

The Wall Street Journal. 2007. "Chinese ATV is Called Hazardous - U.S. Rebuke Adds To Fears Over Safety Of Imported Goods," 6 June.

The Wall Street Journal. 2007. "Accident Raises Safety Concerns On Chinese Tires - Up to 450,000 Imports May Contain a Defect; Obstacles to a Recall,” 26 June.

Yu, Zhihao. 2005. "Trade, Market Size, and Industrial Structure: Revisiting the Home Market Effect." Canadian Journal of Economics 38(1): 255-272. 


\section{A Appendix}

\section{A.1 Proofs}

\section{Proof of Proposition 1}

We look at the trade balance in the differentiated goods from the perspective of country $i$. The countrywide revenues from sales of differentiated goods are $N_{i} c_{i, i} p_{i, i}+N_{i} c_{j, i} p_{j, i}$ whereas the expenditures on the differentiated good are $N_{i} c_{i, i} p_{i, i}+N_{j} c_{i, j} p_{i, j}$. The net exports of differentiated goods are $N_{i} c_{j, i} p_{j, i}-N_{j} c_{i, j} p_{i, j}$. We can rewrite this as

$$
\begin{aligned}
& N_{i} c_{j, i} p_{j, i}-N_{j} c_{i, j} p_{i, j} \\
= & N_{i} \frac{L_{j} \gamma}{\left(N_{i} \tau^{-\frac{\sigma}{1-\sigma}}+N_{j}\right)\left(\frac{w}{\sigma}\right)^{-\frac{\sigma}{1-\sigma}}}\left(\frac{\tau w}{\sigma}\right)^{-\frac{1}{1-\sigma}}-N_{j} \frac{L_{i} \gamma}{\left(N_{i}+N_{j} \tau^{-\frac{\sigma}{1-\sigma}}\right)\left(\frac{w}{\sigma}\right)^{-\frac{\sigma}{1-\sigma}}}\left(\frac{\tau w}{\sigma}\right)^{-\frac{1}{1-\sigma}} \\
= & \left(N_{i} \frac{L_{j}}{\left(N_{i} \tau^{-\frac{\sigma}{1-\sigma}}+N_{j}\right)}-N_{j} \frac{L_{i}}{\left(N_{i}+N_{j} \tau^{-\frac{\sigma}{1-\sigma}}\right)}\right) \tau^{-\frac{1}{1-\sigma}} \sigma \gamma
\end{aligned}
$$

Substituting for $N_{j}=N_{i} \frac{\left(L_{j}-L_{i} \tau^{-\frac{\sigma}{1-\sigma}}\right)}{\left(L_{i}-\tau^{-\frac{\sigma}{1-\sigma}} L_{j}\right)} \tau^{-\frac{\sigma}{1-\sigma}}$ (immediately we note that if $L_{i}>L_{j}$ then $N_{i}>N_{j}$.)

$$
\begin{aligned}
& N_{i} c_{j, i} p_{j, i}-N_{j} c_{i, j} p_{i, j} \\
& =\left(N_{i} \frac{L_{j}}{N_{i} \tau^{-\frac{\sigma}{1-\sigma}}+N_{i} \frac{\left(L_{j}-L_{i} \tau^{-\frac{\sigma}{1-\sigma}}\right)}{\left(L_{i}-\tau^{-\frac{\sigma}{1-\sigma}} L_{j}\right)}}-N_{i} \frac{\left(L_{j}-L_{i} \tau^{-\frac{\sigma}{1-\sigma}}\right)}{\left(L_{i}-\tau^{-\frac{\sigma}{1-\sigma}} L_{j}\right)} \frac{L_{i}}{N_{i}+N_{i} \frac{\left(L_{j}-L_{i} \tau^{-\frac{\sigma}{1-\sigma}}\right)}{\left(L_{i}-\tau^{-\frac{\sigma}{1-\sigma}} L_{j}\right)} \tau^{-\frac{\sigma}{1-\sigma}}}\right) \tau^{-\frac{1}{1-\sigma}} \sigma \gamma \\
& =\left(\frac{\left(L_{i}-\tau^{-\frac{\sigma}{1-\sigma}} L_{j}\right)}{\left(1-\tau^{-\frac{2 \sigma}{1-\sigma}}\right)}-\frac{\left(L_{j}-L_{i} \tau^{-\frac{\sigma}{1-\sigma}}\right)}{\left(1-\tau^{-\frac{2 \sigma}{1-\sigma}}\right)}\right) \tau^{-\frac{1}{1-\sigma}} \sigma \gamma \\
& =\left(L_{i}-L_{j}\right) \frac{\tau^{-\frac{1}{1-\sigma}} \sigma \gamma}{\left(1-\tau^{-\frac{\sigma}{1-\sigma}}\right)} \text {. }
\end{aligned}
$$

Hence, if $L_{i}-L_{j}>0$ then $N_{i} c_{j, i} p_{j, i}-N_{j} c_{i, j}>0$. 


\section{Proof of Proposition 2}

Substitute in (30) for $\left(p_{L}-\psi_{L}\right) q_{i, i}\left(p_{L}\right)$ assuming that condition (28) holds with equality.

$$
\begin{gathered}
\left(\begin{array}{c}
\frac{\left(p_{H}-\psi_{H}\right)}{1-\delta} q_{i, i}\left(p_{H}\right) \\
+\tau \frac{\left(p_{H}-\psi_{H}\right)}{1-\delta} q_{j, i}\left(\tau p_{H}\right)
\end{array}\right)>\left(\begin{array}{c}
\frac{\left(p_{H}-\psi_{H}\right)}{1-\delta} q_{i, i}\left(p_{H}\right)+\frac{\left(p_{H}-\psi_{H}\right)}{1-\delta} q_{j, i}\left(p_{H}\right) \\
-\left(p_{L}-\psi_{L}\right) q_{j, i}\left(p_{L}\right)+\tau \rho\left(p_{L}-\psi_{L}\right) q_{j, i}\left(\tau p_{L}\right)
\end{array}\right) \\
\tau \frac{\left(p_{H}-\psi_{H}\right)}{1-\delta} q_{j, i}\left(\tau p_{H}\right)>\left(\begin{array}{c}
\frac{\left(p_{H}-\psi_{H}\right)}{1-\delta} q_{j, i}\left(p_{H}\right)-\left(p_{L}-\psi_{L}\right) q_{j, i}\left(p_{L}\right) \\
+\tau \rho\left(p_{L}-\psi_{L}\right) q_{j, i}\left(\tau p_{L}\right)
\end{array}\right) .
\end{gathered}
$$

We observe that $\frac{\left(p_{H}-\psi_{H}\right)}{1-\delta} q_{j, i}\left(p_{H}\right)-\left(p_{L}-\psi_{L}\right) q_{j, i}\left(p_{L}\right)=0$ as this can be rewritten

$$
\frac{(1-\sigma(N))}{\sigma(N)} Z_{j}\left(\frac{1}{1-\delta}\left(\psi_{H}\right)^{-\frac{\sigma(N)}{1-\sigma(N)}}-\left(\psi_{L}\right)^{-\frac{\sigma(N)}{1-\sigma(N)}}\right)
$$

and if (28) holds then $\left(\frac{1}{1-\delta}\left(\psi_{H}\right)^{-\frac{\sigma(N)}{1-\sigma(N)}}-\left(\psi_{L}\right)^{-\frac{\sigma(N)}{1-\sigma(N)}}\right)=0$.

Therefore

$$
\begin{aligned}
\frac{\left(p_{H}-\psi_{H}\right)}{1-\delta} q_{j, i}\left(\tau p_{H}\right) & >\rho\left(p_{L}-\psi_{L}\right) q_{j, i}\left(\tau p_{L}\right) \\
\frac{\left(p_{H}-\psi_{H}\right)}{1-\delta}\left(\psi_{H}\right)^{-\frac{\sigma(N)}{1-\sigma(N)}} & >\rho\left(\psi_{L}\right)^{-\frac{\sigma(N)}{1-\sigma(N)}}
\end{aligned}
$$

where the last is true because of the assumption that $\rho<1$.

\section{Proof of Proposition 3}

Inspecting the net trade in differentiated goods, we have to evaluate $N_{i} c_{j i} p_{j i}-N_{j} c_{i j} p_{i j}$. After substituting for demand, prices and the number of firms in country $j$ we are interested in the sign of

$$
\begin{aligned}
& N_{i} c_{j, i} p_{j, i}-N_{j} c_{i, j} p_{i, j} \\
= & N_{i} \frac{L_{j}}{N_{i} \tau^{-\frac{\sigma}{1-\sigma}}+N_{j}}-N_{j} \frac{L_{i}}{N_{i}+N_{j} \tau^{-\frac{\sigma}{1-\sigma}}} \\
= & N_{i} \frac{L_{j}}{N_{i} \tau^{-\frac{\sigma}{1-\sigma}}+N_{i} \frac{\left(L_{j}-L_{i} \tau^{-\frac{\sigma}{1-\sigma}}\right)}{\left(L_{i}-\tau^{-\frac{\sigma}{1-\sigma}} L_{j}\right)}}-N_{i} \frac{\left(L_{j}-L_{i} \tau^{-\frac{\sigma}{1-\sigma}}\right)}{\left(L_{i}-\tau^{-\frac{\sigma}{1-\sigma}} L_{j}\right)} \frac{L_{i}}{N_{i}+N_{i} \frac{\left(L_{j}-L_{i} \tau^{-\frac{\sigma}{1-\sigma}}\right)}{\left(L_{i}-\tau^{-\frac{\sigma}{1-\sigma}} L_{j}\right)} \tau^{-\frac{\sigma}{1-\sigma}}} \\
= & \frac{\left(L_{i}-\tau^{-\frac{\sigma}{1-\sigma}} L_{j}\right)}{\left(1-\tau^{-\frac{2 \sigma}{1-\sigma}}\right)}-\frac{\left(L_{j}-L_{i} \tau^{-\frac{\sigma}{1-\sigma}}\right)}{\left(1-\tau^{-\frac{j \sigma}{1-\sigma}}\right)} \\
= & \frac{\left(L_{i}-L_{j}\right)}{\left(1-\tau^{-\frac{\sigma}{1-\sigma}}\right)}
\end{aligned}
$$


so the country with the larger population has a positive net trade balance in the differentiated good.

\section{A.2 The home market effect and decreasing returns to scale}

We construct an example where the home market effect holds and the technologies employed by firms exhibit decreasing returns to scale. Consider the market situation described in section 2. Suppose $\alpha=1$ and that $\psi_{H}(q)=\psi_{H}(q(p))^{\mu}$ and $\psi_{L}(q)=\psi_{L}(q(p))^{\mu}$ with $\mu>1$ but that $\mu<\frac{\beta}{2}+1$. Therefore both the production of the high and low quality good exhibit decreasing returns to scale. The incentive compatibility condition for firms in a single market can be rewritten as $\frac{\varpi}{\left(\psi_{H}-\psi_{L}\right)} \geq \frac{(q(p))^{\beta}+1}{(q(p))^{1+\beta-\mu}}$. For $\mu<\frac{\beta}{2}+1$ as $q(p) \rightarrow 0$ the right hand side converges to infinity. Hence, the incentive compatibility constraint cannot hold as the firm's production would become arbitrarily small and there is a minimum size of production required from each firm to produce a high quality good. Similarly, if there is international trade allowed set up as in section 3.1 the incentive compatibility condition for the firm can be rewritten as $\frac{\varpi}{\left(\psi_{H}-\psi_{L}\right)} \geq \frac{\left(q_{i, i}\left(p_{i}\right)+\tau q_{j, i}\left(\tau p_{i}\right)\right)^{\mu-1}\left(\left(q_{i, i}\left(p_{i}\right)+q_{j, i}\left(\tau p_{i}\right)\right)^{\beta}+1\right)}{\left(q_{i, i}\left(p_{i}\right)+q_{j, i}\left(\tau p_{i}\right)\right)^{\beta}}$. With $\mu<\frac{\beta}{2}+1$ again there is a minimum size requirement for producing high quality in a zero profit equilibrium. Consequently, one can show that in this setup the home market effect will hold. Therefore, Krugman's (1980) statement that "in a world of diminishing returns strong domestic demand for a good will tend to make it an import rather than an export" does not hold in the present context. 